\title{
Results of Calculation of Transonic Gas Flow in a Flat Channel Separated by Perforated Walls
}

\author{
E.Yu. Arhireeva ${ }^{1}$, B.N. Dankov ${ }^{1}$, A.V. Panasenko ${ }^{2}$ \\ ${ }^{1}$ Central Research Institute of Machine Building, \\ Korolev, Moscow region, 141074, Russia \\ ${ }^{2}$ Ishlinsky Institute for Problems in Mechanics, Russian Academy of Sciences, \\ Moscow, 119526, Russia \\ akpanas@mail.ru
}

\begin{abstract}
The results of mathematical modeling of viscous gas flow in a flat channel separated by perforated walls on the base of Navier-Stokes equations with Reynolds number $10^{6}$ are presented. The presence of perforated walls leads to the formation of a complex vortex flow around them.
\end{abstract}

Keywords: gas flows in a flat channel with perforated walls.

The presence of holes in the perforated walls leads to gas flowing into the upper and lower parts of the channel. The gas moves up and down, flowing through the holes in the perforated walls to the lower and upper parts of the channel.

As a result of the movement of gas back and forth through the holes in the perforated walls, the flow in the upper and lower areas of the channel becomes vortex. In this case, a stable vortex structure is formed in the upper part of the channel above the perforated barrier. In the lower part of the channel under the perforated wall, a vortex structure is also formed, which undergoes changes over time.
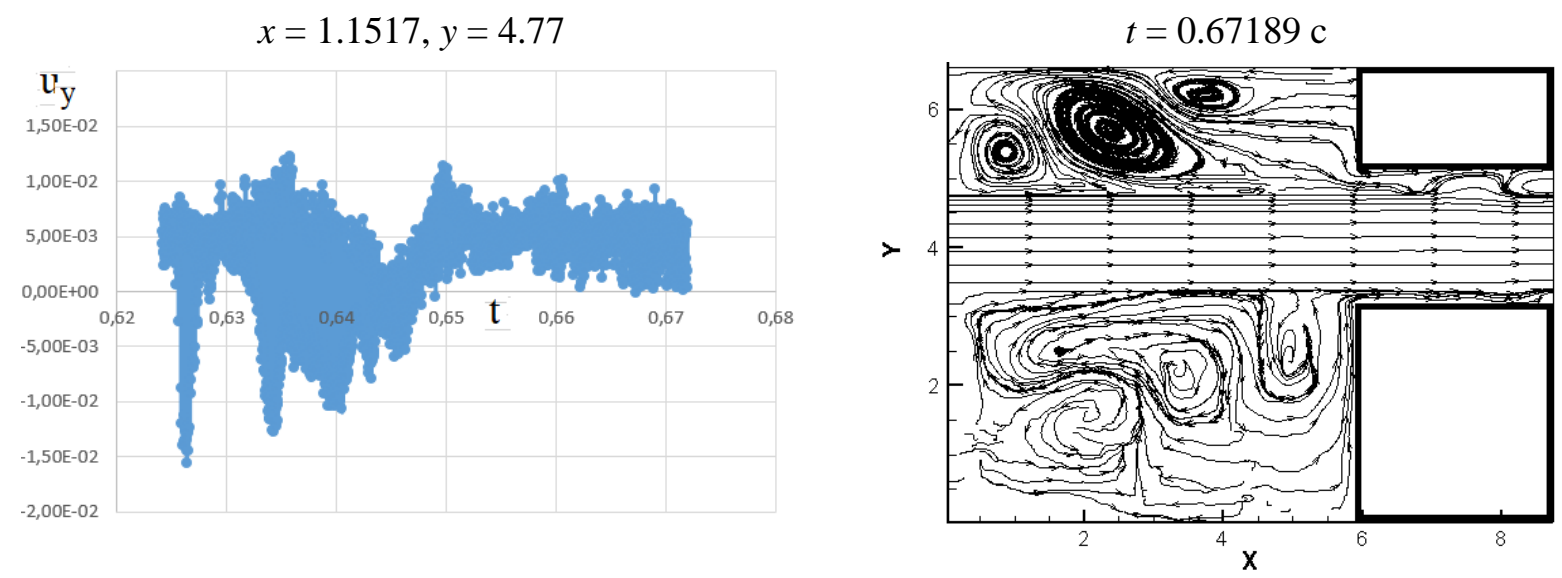

The time dependence of the component of the velocity $u_{y}$ in the hole of a perforated barrier.

Picture of current lines 


\title{
Результаты расчета трансзвукового течения газа в плоском канале, разделенном перфорированными стенками
}

\author{
Е.Ю. Архиреева ${ }^{1}$, Б.Н. Даньков ${ }^{1}$, А.В. Панасенко ${ }^{2}$ \\ ${ }^{1}$ ФГУП «Центральный научно-исследовательский институт машиностроения», \\ Россия, Королёв, 141074, Пионерская ул., 4 \\ ${ }^{2}$ Институт проблем механики им. А.Ю. Иилинского РАН, \\ Россия, Москва, 119526, пр-т Вернадского, д.101, корп.1 \\ akpanas@mail.ru
}

\begin{abstract}
Аннотация
Приведены результаты математического моделирования вязкого течения газа в плоском канале, разделенном перфорированными стенками, с использованием уравнений Навье-Стокса, при числе Рейнольдса $10^{6}$. Показано, что наличие перфорированных стенок приводит к формированию сложного вихревого течения вблизи этих преград.
\end{abstract}

Ключевые слова: течения газа в плоском канале с учетом перфорированных стенок.

\section{1. Введение}

Успешное проведение экспериментальных исследований зависит от возможности устранения влияния на результат различных возмущающих течение газа особенностей устройства аэродинамических установок $[1,2]$. Например, при исследовании течений газа в трансзвуковой аэродинамической трубе, влияние на них оказывают перфорированные стенки, ограничивающие поток в рабочей ее части, задачей которых является снижение возмущающего воздействия на поток.

\section{2. Постановка задачи и методы расчета}

Рассматривается аналог трансзвуковой аэродинамической трубы в виде двумерного канала, который имеет верхнюю и нижнюю составляющие, отделенные от него перфорированными преградами с отверстиями, как показано на рис. 1. Ось $X$ направлена по потоку газа, ось $Y$ - в вертикальном направлении, ось $Z$ - поперек потока. До запуска потока в канал газ покоится при нормальных атмосферных условиях. На всех твердых границах канала ABCDE и FGKLM ставятся условия прилипания газа при поддержании температуры $300 \mathrm{~K}$. Поток газа с числом Маха 0.98 при давлении $P_{0}=101325 \mathrm{H} / \mathrm{M}^{2}$ подается между перфорированной границей на участке AM и вытекает на участке границы EF с поддержанием граничного условия его сноса.

Все представленные ниже параметры отнесены к невозмущенным значениям давления, плотности и линейному размеру 1 м.

Использовалась расчетная сетка с количеством узлов 1161600. Сетка задавалась с постоянным шагом со сгущением ее по обе стороны перфорированных преград и в окрестности стенок канала с обеспечением расчетного шага, соответствующего учету пограничного слоя при числе Рейнольдса $10^{6}$. На перфорированных преградах было задано по 12 отверстий с размером каждого 0.21 м. 
Численные исследования были проведены на основе использования модифицированной схемы типа [3] в не погранслойной части течения. При этом диффузионные члены аппроксимировались центральными разностями второго порядка точности. В области пограничного слоя использовалась разностная схема высокого порядка точности [4] с использованием данных, полученных по схеме типа [3] при расчете вне пограничного слоя.

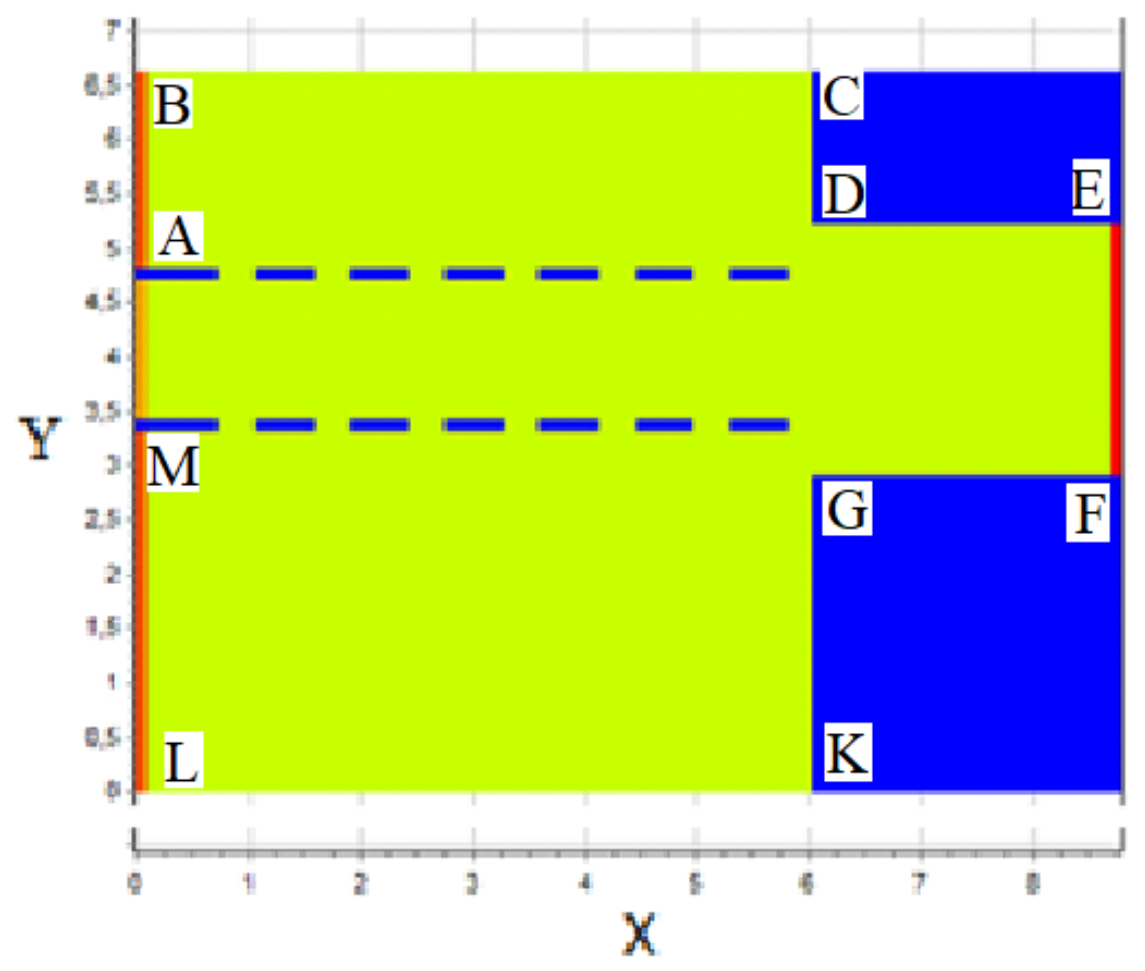

Рис. 1. Вертикальное сечение канала

\section{3. Результаты расчетов}

Наличие отверстий в перфорированных стенках приводит к затеканию газа в верхнюю и нижнюю секции перегороженного канала. На рис. 2, в зависимости от времени (в секундах), показано поведение компоненты скорости $u_{y}$ при различных значениях координат $x, y$. Направление потока в рассматриваемых точках изменяется с течением времени. Газ движется вверх-вниз, перетекая через отверстия в перфорированных стенках в нижнюю и верхнюю части канала

В результате движения газа туда-обратно через отверстия в перфорированных преградах, течение в верхней и нижней областях канала приобретает завихренный характер, как это видно из рис. 3. При этом в верхней части канала над перфорированной преградой образуется устойчивая вихревая структура. В нижней части канала под перфорированной преградой также образуется вихревая структура, претерпевающая изменения с течением времени. 

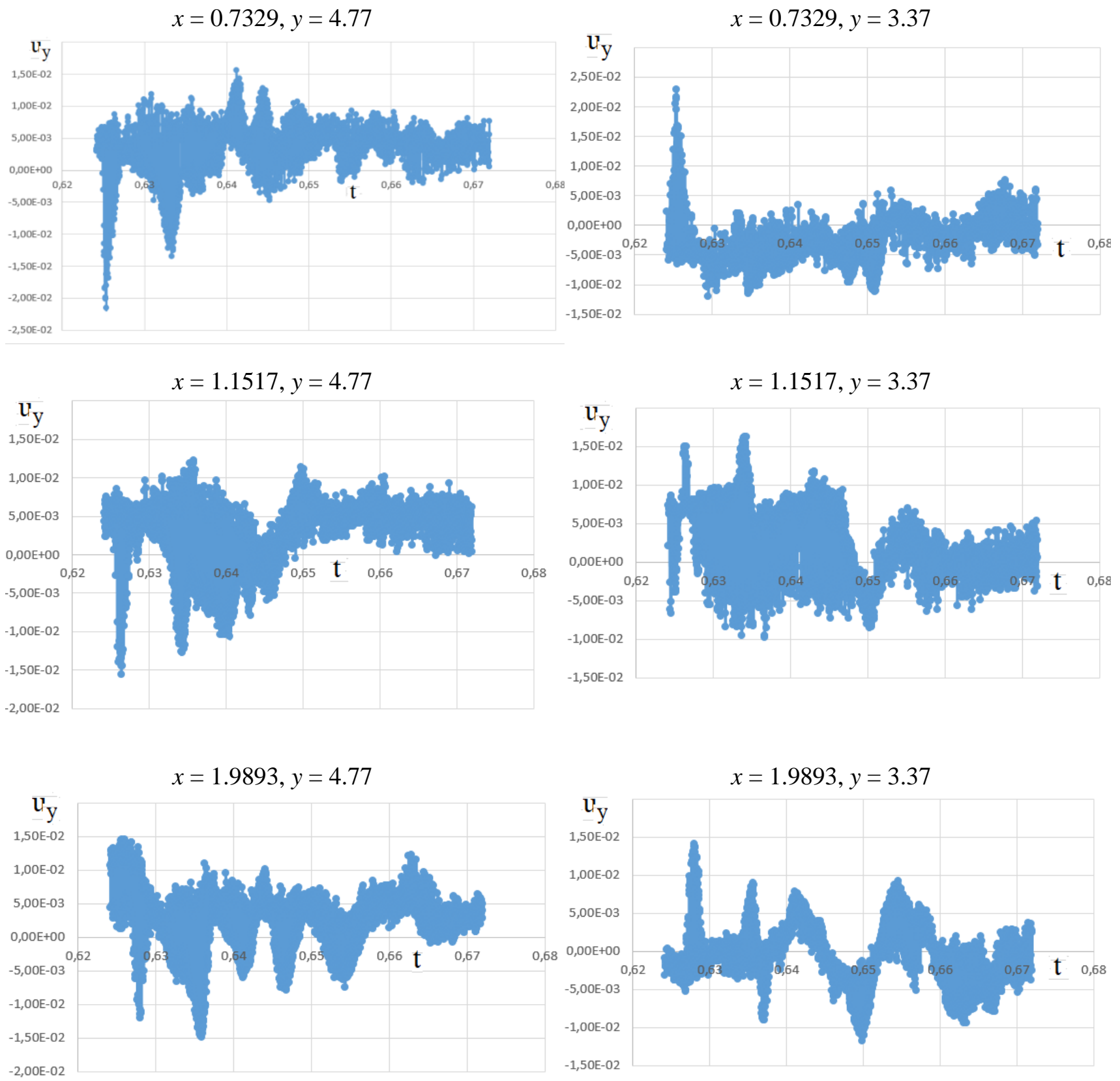

Рис. 2. Зависимость от времени компоненты скорости $u_{y}$ в нескольких отверстиях перфорированной преграды 

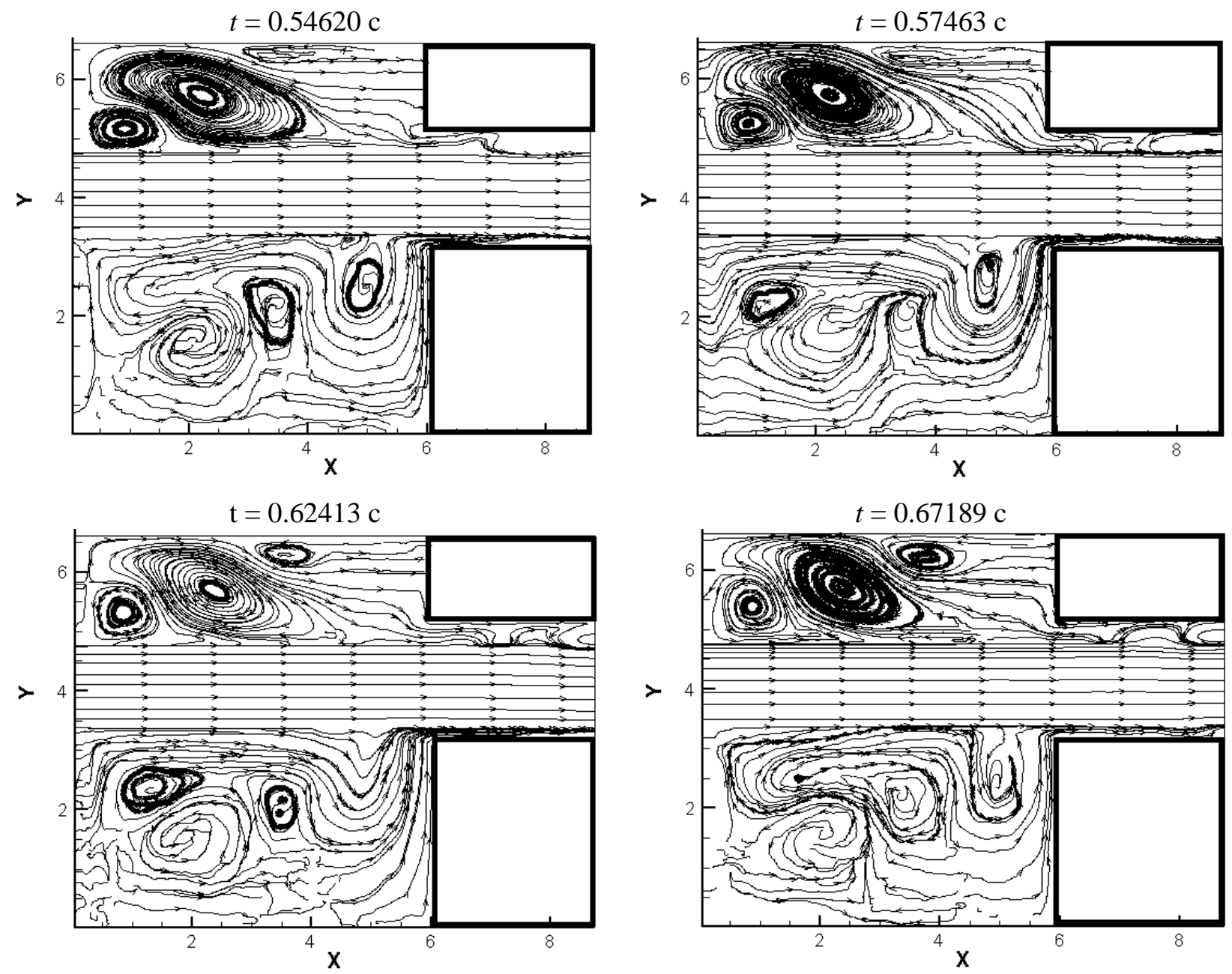

Рис. 3. Картина линий тока

\section{4. Заключение}

Результаты расчетов течения в канале на основе уравнений Навье-Стокса показали влияние перфорированных стенок на формирование вихревого потока в верхней и нижней областях перегороженного канала.

Работа выполнена в рамках гранта РФФИ №17-08-00909 А. Вычисления проводились на суперкомпьютере МСЦ РАН.

\section{Литература}

1. А.И. Иванов Экспериментальное исследование течения газа вблизи перфорированных стенок трансзвуковой ударной трубы // Ученые записки ЦАГИ. 1987. Т. ХҮІІІ. №3. С. 131-235.

2. M.A. Kotov, I.A. Kryukov, L.B. Ruleva, S.I. Solodovnikov, S.T. Surzhikov. Multiple Flow Regimes in a Single Hypersonic Shock Tube Experiment // AIAA 2014-2657. 22 p.

3. R.W. Mac-Cormak.The effect of viscosity in hypervelocity impact cratering // AIAA Paper, 1969, pp. 69-354.

4. R. Kamakoti and C. Pantano, High-order narrow stencil finite-difference approximations of secondorder derivatives involving variable coefficients, SIAM Journal on Scientific Computing, 31 (2010), pp. $4222-4243$. 